\title{
Green Economy and Social Responsibility in the Italian agri-food sector: the focus on the wine sector.
}

\author{
Fabio Amatucci ${ }^{\text {a,*, Anna Maria Pascale }}{ }^{\text {b,* }}$, Maria Carmela Serluca ${ }^{\text {b,* }}$ \\ a University of Sannio, Benevento, and CERGAS Bocconi University, Milan \\ bUniversity of Sannio, Benevento, Italy
}

\begin{abstract}
A B S T R A C T
This paper aims at investigating the reasons why the environmental variable and issues - such as sustainability, social responsibility and all those behaviours that can be attributed to the general definition of Green Economy - , are generally covering a more and more marked and growing influence on the contemporary economy and, in particular, entrepreneurial behaviour. Our intention is to underline how the integration between business ethics and value creation has become inescapable for the business realities, not only to withstand the competition, but also to ensure the survival itself. After a general overview, it has been decided to focus the analysis on the impact that these issues have on a sector such as agri-food in general and wine in particular, which, paradoxically, are the ones that for long time have shown little sensitive towards the above-mentioned issues. The objective of this work was to highlight the importance for contemporary business realities, to pursue the integration of the social and corporate strategies, including environmental performance, economic results and competitive enterprise. The set of human activities, technological progress and the uncontrolled exploitation of resources has led to heavy imbalances in the terrestrial ecosystem, risking compromising the ability of future generations to meet their own needs. One possible solution is, therefore, represented by the sustainable development and the desire to pursue economic growth compatible with social equity. In this context, sustainability, lived in the past as more ethical than economic, is gaining importance and a much more concrete profile, designed to produce economic returns as well as on image.
\end{abstract}

ARTICLE INFO

Keywords:

business ethics, green economy, sustainability, social and corporate strategies, sustainable development, value creation, wine sector

*Corresponding author:

Article history:

Article Submitted 11-02-2015

Article Accepted 20-03-2015

**Article previously published in EJEM 2015, vol 2, No. 2

\section{INTRODUCTION}

The profound changes that characterize the contemporary reality have been changing irreversibly our daily way of life, thinking and perceiving the world and human society. Global warming has been for long time a topic that requires a global and deep rethinking on the sustainability of our current development model; the financial crisis has been a shock so 
strong to create a clear discontinuity of perception and feeling, showing an even more growing interest in the issue of sustainability.

The signals of actuality of the theme can be readily observed both in the increasing attention from consumers, - especially in those more informed and evolved segments-, in the growing media coverage and political attention on ecological issues, as well as in the economic ethics; in the presence, again, of the theme in the communication of many companies and in the assumption by investors of sustainability as a criterion to evaluate the enterprises solidity and, finally, in the experimentation of a possible "system break" both from a financial and scarcity of resources (water, oil, ...) point of view (water, oil, ...).

From a theoretical point of view, sustainability remains a strong and ideal values, a commitment to future generations to preserve the environment by limiting the exploitation of resources and reducing the environmental impact of products and processes. Moreover, sustainability is also a commitment to the community through an economic activity able, at least partially, to return to the community and the territory what it has received from them. In practice, it means that the company has to propose a business capable of being renewed and long-lasting: to operate by taking into account the resources (financial and environmental) actually available and act responsibly towards all its stakeholders (consumers/customers, employees, territories in which the company operates) with regard to environment, safety, social and cultural cohesion).

This paper aims at offering a detailed analysis of possible instruments and the different strategies that, with regard to environmental, social, territorial, are able to enhance in a sustainable manner the food quality by encouraging the development of a sustainable culture. After a general overview on the concept of sustainability and, therefore, on a different approach to the same way of doing business, we focus on the issues and on the instruments of CSR food highlighting in particular the contribution it can make to business competitiveness food.

The last part of the paper is focused on the business of green wine. In fact, the wine sector is an area of great significance in the Italian food system. It is the reason why it is absolutely relevant investigating, in the light of the above disclosure, if there are conditions in the cultivation Italian wine able not only to meet the requirements of quality and price demanded by the market, but also to protect the environment and health through sustainable 
development.

Therefore, in this paper the research questions are essentially two:

"What is the conceptual framework in which to contextualize the strategies and tools for the sustainable exploitation in the food industry?" and "Since the Italian wine industry is very important especially in terms of export, what may be the economic consequences on the economic results and the business strategies by using modern methods of organic agriculture respectful of the precepts of social responsibility?".

The methodology used in order to write this paper is deductive. Moreover, this investigation has been based on the analysis of the literature about the subject of corporate social responsibility, in the food industry and in particular in the wine sector.

\section{SUSTAINABILITY AS A POSSIBLE SOLUTION TO THE ECONOMIC CRISIS}

In the context in which we live, characterized by a heavy financial and economic crisis of devastating effects, reflection on a "future model" of business appears as necessary as inevitable. In this perspective, sustainability, thought in the past as more "ethical" than economic, has acquired a new importance and a much more concrete profile these days. In fact, sustainability not only seems to be less utopian, but also a theme of necessary and realistic redesign that might produce, in due course, economic returns as well as on image.

The spread of social responsibility is part (Jain et al., 2010, pp. 42-43) of the cultural evolution of our society, acting as a challenge to capture quickly and with foresight. It is necessary that companies resize on real resources, living the sustainability as an opportunity and not as a constraint and cost, and recreating a new relationship with the society in which they operate (Jain et al., 2010, pp. 44-45).

It seems necessary, then, a redefinition of evaluating criteria and parameters of companies solidity: sustainability has to become an element of rating for investors use. It is a challenge that requires wide unusual horizons and the full involvement of all social actors: companies, which have to be able to combine the pursuit of profit with a vision founded on the centrality of the person; institutions, which have to be guarantors of an environment favorable to the development of CSR (Corporate Social Responsibility) and, last but not least, civil society 
must provide the right incentives and impulses to the world of business and management.

A challenge, then, that needs tools and practice; communication and leadership (Beda and Bodo, 2006). To advance CSR it is necessary a large awareness of the relationship between business and society and, at the same time, a rooted adherence to the strategies and activities of companies (... ) (Porter and Kaplan, 2006).

The integration between the business and society needs requires good intentions and strong leadership. It requires adjustments in organization, relations and "incentives"; joining philanthropic activities with the management of the social impact, instilling a social dimension into business activities: in this way CSR policies can be an effective tool for the enhancement of people, knowledge and the knowledge encoded in the same organizational structures.

The integration of social and environmental considerations in decision-making and relationships with stakeholders requires, then, not only a change of mindset and guidance of the people, but also the acquisition of a new cultural sensibility and a wealth of knowledge that can involve all organizational components. This requires an ability to promote transparency and introspection of the company that increasingly looks inside itself, realizing that innovating, having a good reputation and a good level of sustainability are essential conditions to become a company capable of enduring benefit.

It follows that the interpretation of corporate social responsibility as a strategic driver for the development of people is now more than ever important for organization competitive success. In this perspective, top managers and those who manage and coordinate the people in the company, must be the promoters of CSR strategies capable of stimulating members of the organization to learn new ways of doing business and, later, of consolidating practices and values compatible with the expectations of the social partners: only in this way the CSR strategies will increase with more strength and incisiveness (Cocozza, 2010).

The CRS is achieved through the adoption of voluntary actions and strategies that tend to improve the social and environmental quality (Dupuis, 2005).

For all those businesses that operate in the food sector, the environmental dimension has crucial importance (Trisorio, 2004). The impact of agriculture occurs on multiple components: air, soil, water, biodiversity and landscape (Romano, 1998 Signorello et al., 
2004). Its protection is not left to the initiative of free enterprise, but today falls increasingly on the political agenda not only of individual countries, but also of European policies that set limits and try to contain the effects of negative externalities $\left(\mathrm{N}_{2} \mathrm{O}\right.$ emissions and $\mathrm{CH}_{4}$, water pollution, soil contamination, depletion of the landscape) (Briamonte et al., 2008). In Italy, the National Action Plan on Corporate Social Responsibility 2012-2014 identifies the strategies of the Italian State in order to create a more favorable environment to the behaviors of CSR volunteers, whose objectives are to increase the culture of responsibility in business, citizens; to support businesses that adopt CSR; to contribute to the strengthening of market incentives for CSR; to promote transparency and disclosure of information. The actions taken will have strong repercussions on reference areas and enhance the overall quality of the product made in Italy.

To support the management-oriented CSR it has to be reminded the UNI ISO 26000 guidelines that aim at "helping organizations to go beyond mere compliance with the law, promoting a common understanding in the field of social responsibility and integrating other tools and initiatives for Social Responsibility, but not substituting for them” (UNI EN ISO 26000). In it are identified seven principles of social responsibility:

1. Accountability;

2. Transparency

3. Ethical behavior

4. Respecting the interests of stakeholders;

5. Respect for the principle of legality;

6. Compliance with international norms of behavior

7. Respect for human rights.

Among the tools by which an organization is able to report in a transparent manner their own path of social responsibility is the sustainability report (Castellani, 2011, Campedelli, 2005). 


\section{SUSTAINABLE ENTREPRENEURSHIP}

Previous sections show the need of a new approach to action by the company, an action that takes into account the interests of all its stakeholders and the impact of a social and environmental impacts that may have in the medium - long term.

A different approach to the same way of doing business involves, however, not only a change in strategic and economic decisions, but also a transformation of the organizational culture which takes new values and points of reference and adopts different strategies communication both inwards and outside.

The company, facing the need to make sense of the reality that is changing, starts to produce new cognitive maps by means of which defines its vision and mission. It follows that the introduction of socially responsible approaches within a company gives an impetus to the creation of an organizational culture centered on new values. Companies are no longer judged only for their economic performance, but also for the way in which the result has been achieved, both in terms of quality of products and services offered and both in terms of fairness and transparency of the conduct taken against their public and private stakeholders.

Entrepreneurship socially responsible is, therefore, the integration of ethical concerns within the strategic vision of the company: it is a manifestation of the will of large, small and medium-sized enterprises to effectively manage the issues of ethic and social impact in them and in the areas of activity. The inclusion of the environmental variable in every business decision gives rise to a new approach in the definition of business strategies: the green/environmental management, a management model in which the firm represents a point of reference for all those involved in environmental concerns as it has the responsibility to define programs and introduce management tools that may themselves be models able to influence all players in the network. 


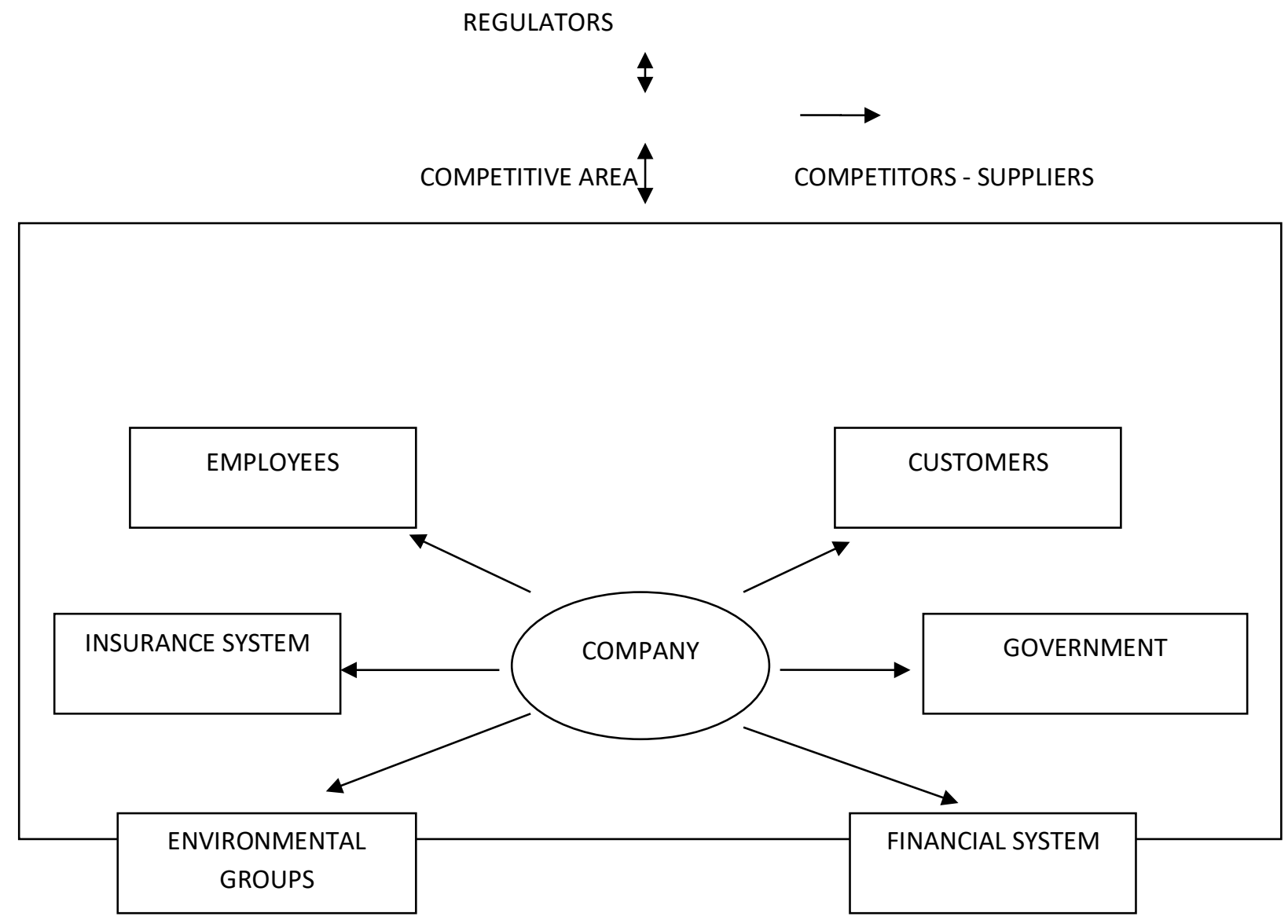

Figure 1: The network of the company.

Source: Bertolini et al., (1996)

A correct and efficient consideration of environmental issues, may:

- become a positive factor for competition against other companies;

- contribute to obtain the highest price-sensitive consumers in revenue in relation to the environmental problem;

- promote a reduction of production costs direct or indirect;

- expand the credibility and social legitimacy of our own business;

-increase confidence and a greater social sharing of our own choices;

- increase the level of identification of people in the enterprise, and their degree of motivation. 


\section{TOOLS FOR SOCIAL RESPONSIBILITY IN THE ITALIAN AGRI-FOOD SECTOR}

The focus on the theme of social responsibility and ethical conscience of companies appears to be a topic of great interest even in a highly strategic sector of our economy: the agri-food system.

In fact, even in this sector the introduction of production processes based on quality has resulted in a substantial change in the production structure and the balance of the market in a more competitive direction; in particular, policies that aim at making strategic use of quality in agriculture, have acted on the level of competition in the sector, through two important variables:

- $\quad$ The ability to control the quality of the producers;

- The level of information on the quality of the agricultural product available to the operators (intermediate or final consumers) that express the question.

Over the years there has been, therefore, an increasing in sensitivity and attention to health and food safety, the environment and the territories (Modenesi et al., 2007). The consumer, more careful and critical, asks more and more often the company for communicating these issues: if in the past it was required agricultural production able to feed the society, later it has been required that such production incorporate the guarantee of safety and health that have to have food in general, up to require a higher and higher quality. These days, the company also requires to the primary sector production techniques that are respectful of natural resources, the environment and the landscape. The needs/expectations of the consumers of these "added value" to the food places, not just individual companies, but entire food system and public policies for the sector, faced with new challenges and, in particular, faced with the necessity to satisfy these needs, in order to strengthen their competitiveness on domestic and international markets.

In this context, CSR is the differentiation strategy that can make the company unique in its sector with particular characteristics recognized and required by the consumer.

The instruments of social responsibility can be traced to responsible management tools that affect the supply side and are designed to support businesses in the integration of the principles of responsibility in strategic and operational processes (codes of conduct, certification) and tools for socially responsible consumption which act on the demand side 
and aim at influencing the choices of consumers (labels, brands) (Briamonte et al., 2008).

\section{Specifically:}

- Human Resources: The human resources development through growth of workers skills as well as through a management policy that takes account of equal opportunities, integration of immigrants and the quality of work (Censis, 2004).

This is a deeply delicate issue. The small size of the business system, in fact, makes it difficult to deal with this problem, which is compounded by the characteristics of the production, plagued by problems such as the low level of security, high seasonality, extensive use of immigrant labour and irregular work. In this sense, CSR can be an important instrument to enhance and develop the changes taking place upstream and downstream, on farms that in some cases pay particular attention to their workers and their working conditions.

- Product: it is absolutely necessary, then, to have an integrated approach to product that takes into account the expectations of consumers about the quality characteristics, territoriality and transparency. With regard to food consumption, the literature shows that consumers tend now to prefer safe products made with environmentally sound techniques and social needs. (Grunert, 2006).This is a product strategy that ensures authenticity, security, but also those elements that give value added services such as identifiable, traceability, innovation and truthfulness of information.

It is worth noting that social responsibility is not measured in relation to the number of instruments adopted, but it represents a new way of managing the corporate activities capable of driving social change and responding to consumer expectations by integrating the system of risk management and opportunities (Briamonte et al., 2008).

It is now popular a growing sensitivity of quality of life that accompanies a more conscious consumption management and a renewed interest in the health and family life (Annunziata, 2011). Consumers and producers are also in agreement that the pursuit of quality can be an important antidote to the dangers of the production approval (Cesaretti et al., 2010). The quality of agro-food products, therefore, has taken a substantial importance in the buying process and helped decline the concept of production in a broader supply and territory dimension. In order to ensure food safety according to an integrated and scientific approach, the European Union has also undertaken the harmonization of national laws on local products -already present in Italy, France and Germany-, by identifying three different levels of 
specificity: designation of origin (PDO), protected Geographical Indication (PGI) and certificate of specificity.

The protected designation of origin (PDO) is attributed to agricultural production and food products whose characteristics are due mainly (though not exclusively) to the geographical environment, "including the natural and human factors". All stages of the production of the raw material, machining and processing, must be done in the area of origin.

The Protected Geographical Indication (PGI) is restricted to products from a particular region. These products have at least one characteristic that binds them to the land of origin. Moreover, it is sufficient that one phase of production, processing and post-processing, takes place in their territory of origin.

The Community legislator, then, has also established a more generic Certificate of Specificity named as "Traditional Speciality Guaranteed" (TSG). The STG is not about the territorial origin of the product, but rather the peculiarities of the raw materials or the manufacturing process and possible subsequent processing.

In addition to the PDO and PGI products, the national legislator (with Legislative Decree n. 173 of 30/04/1998) has also identified an additional category of food products which has strong traditional productive connotations and that do not follow the health rules usually applied in the industrial productions. Moreover, the national legislator has adopted new tools such as specific rules for productive activity, a control systems over the entire food chain (from farm to table) and effective measures able to provide information to the consumers. It makes possible to trace the route of food, animal feeds and their ingredients; in other words it allows to know the reverse route of the product (from the table to the field) and consequently its basic ingredients. It follows that the label is an useful tools for consumers as it gives more accurate information about ingredients, nutritional values and methods of food production and about a whole series of national and international checks organized in order to track cases of adulteration and counterfeit foodstuffs. 


\section{THE GREEN WINE BUSINESS}

According to the Ismea ISTAT data processing that compares the data of January-June 2014 with those of the same period in the last year, it emerged that Italian exports of agri-food products close the first half of 2014 with a rise of 1, 6\% in value, determined exclusively by the good performance of processed foods $(+2.6 \%)$, compared to an interruption of the agricultural exports (-2.7\%). Albeit at a slower pace when compared with the growth rates for the last three years (respectively $+8.7 \%$ in 2011, 5.6\% in 2012 and 4.8\% in 2013), the trend of international sales of the sector is slightly better than the Italian export in general $(+1.3 \%$ in the first half) (Ismea, 2014). The wine sector, in particular, is an area of great significance in the Italian agri-food system. "Wine is one of the Made in Italy ambassadors and Italian companies are showing great skills in dealing with the difficulties of the market, the changes of styles consumption and the competition that comes from countries that only recently are venturing with this ancient art” (Unioncamere, 2009). The world of wine has a turnover in Italy of eight million euro; the entire capital of this industry (including the value of the equipment and facilities related to the production of wines, spirits and liqueurs, balsamic vinegars) is of nearly 50 billion euro. There are 1.2 million people employed in the wine sector, including the stage of the distribution. While the usage of wine is increasing in the world, but slightly decreasing in Europe, Italy confirms itself as the worldwide leader in the production and marketing of wine (nearly one-fifth of the wine sold in the world is made in Italy) behind only France.

In fact, Italy, the second largest exporter of wine with an international level share of $18 \%$, is holder of $61.7 \%$ of the global market share, along with France and Spain, confirming its global leadership in international sales of the wine sector .

Even for Mediobanca (Studio Mediobanca, 2014), the most successful Italian factor of this sector is the export. The first pre-final for the year 2013 reports an increase of $4.8 \%$, more abroad $(+7.7 \%)$ than in Italy $(+1.8 \%)$, compared with the contraction of manufacturing (0,3\%) and a slight improvement from of food industries (+0.3\%). Total sales of 2013 are of $24.1 \%$ above the level of 2008 , the export sales of $40.4 \%$, the national of $10.7 \%$, confirming the trend of the last six years (except 2009).

The 2012 wine sector closed with revenues up 7.7\% on 2011 (+ 9.3\% for exports, $6.1 \%$ in Italy), more than marked by the food industry as a whole $(+2 \%)$ and the beverage $(+4.6 \%)$, 
while the Italian manufacturing industry has contracted (-2.1\%). The growth rates of sales are down from 2011, and are back at 2010 levels. The European Union remains by far the most important area for the export of Italian wines, accounting for more than half of total exports, $51 \%$, an increase in value of $9.2 \%$ on 2012 when it accounted for $50.5 \%$. The second target area is North America, which accounts for 32.7\% of exports (34\% in 2012), an increase of 3.9\%; Asia and Australia are up 11.3\%, although with limited weight equal to 4.3\%. Finally, the contribution remains marginal in Latin America (1.4\%), while the rest of the world (Africa, Middle East and European countries outside the EU) amounts to $10.6 \%$ (10\% in 2012), an increase of $14.9 \%$.

Table 1.: "Assoenologi" forecast on wine production in 2014 by region (compared with the average of the last 5 years and 2013)

\begin{tabular}{|c|c|c|c|c|c|}
\hline REGION & $\begin{array}{c}\text { Average } \\
\text { production } \\
2009 / 20013 \\
\text { (Sourse ISTAT) }\end{array}$ & $\begin{array}{c}\text { hl production } \\
2013 \\
\text { (suorce ISTAT) }\end{array}$ & $\begin{array}{l}\text { +/- \% expected } \\
\text { compared to the } \\
\text { average of the } \\
\text { last } 5 \text { years }\end{array}$ & $\begin{array}{c}\text { +/-\% expected } \\
\text { compared } \\
2013\end{array}$ & $\begin{array}{c}\text { Everage hl } \\
\text { expeted } \\
2014^{*}\end{array}$ \\
\hline PIEMONTE & 2.697 .000 & 2.580 .000 & $-14 \%$ & $-10 \%$ & 2.330 .000 \\
\hline LOMBARDIA & 1.292 .000 & 1.301 .000 & $-14 \%$ & $-15 \%$ & 1.110 .000 \\
\hline TRENTINO & 1.220 .000 & 1.362 .000 & $-5 \%$ & $-15 \%$ & 1.160 .000 \\
\hline VENETO & 8.425 .000 & 9.148 .000 & $-8 \%$ & $-15 \%$ & 7.780 .000 \\
\hline FRIULI V.G. & 1.217 .000 & 1.173 .000 & $-13 \%$ & $-10 \%$ & 1.060 .000 \\
\hline $\begin{array}{l}\text { EMILIA } \\
\text { ROMAGNA }\end{array}$ & 6.735 .000 & 7.396 .000 & $-1 \%$ & $-10 \%$ & 6.660 .000 \\
\hline TOSCANA & 2.576 .000 & 2.657 .000 & $+5 \%$ & $+10 \%$ & 2.700 .000 \\
\hline MARCHE & 881.000 & 1.039 .000 & $+24 \%$ & $+5 \%$ & 1.090 .000 \\
\hline LAZIO/UMBRIA & 2.237 .000 & 2.472 .000 & $+22 \%$ & $+10 \%$ & 2.720 .000 \\
\hline ABRUZZO & 2.627 .000 & 2.728 .000 & $-6 \%$ & $-10 \%$ & 2.460 .000 \\
\hline CAMPANIA & 1.722 .000 & 1.644 .000 & $-23 \%$ & $-20 \%$ & 1.320 .000 \\
\hline PUGLIA & 6.022 .000 & 5.908 .000 & $-21 \%$ & $-20 \%$ & 4.730 .000 \\
\hline SICILIA & 5.825 .000 & 7.282 .000 & $-12 \%$ & $-30 \%$ & 5.100 .000 \\
\hline SARDEGMA & 530.000 & 530.000 & $+9 \%$ & $-10 \%$ & 580.000 \\
\hline ALTRE** & 889.000 & 933.000 & $-10 \%$ & $-15 \%$ & 800.000 \\
\hline TOTALE & 44.895 .000 & 48.161 .000 & $-7 \%$ & $-13,5 \%$ & 41.600 .000 \\
\hline
\end{tabular}

* Average productive presumed for each region

** (Valle d'Aosta, Liguria, Molise, Basilicata, Calabria) 
Table 2.: Total Export Italian Wine January-June 2010/2014 *

\begin{tabular}{|l|c|c|c|c|c|c|}
\hline & 2010 gen giu & 2011 gen giu & 2012 gen giu & 2013 gen giu & 2014 gen giu & Val Var \% gen giu 13/14 \\
\hline Mondo Valore & 1.776 & 2.026 & 2.169 & 2.351 & 2.387 & $1,5 \%$ \\
\hline Mondo Volume & 10.035 & 11.295 & 10.176 & $9.858,9$ & $9.946,5$ & $0,9 \%$ \\
\hline Mondo VMU & 1,77 & 1,79 & 2,13 & 2,38 & 2,40 & $0,6 \%$ \\
\hline
\end{tabular}

* Amounts in millions of euro // Volume in thousands of hectoliters VMU € / liter

Today, wine production has to meet not only those quality and price requirements necessary to satisfy market needs, but it must also follow a series of increasingly stringent standards imposed by the Italian and European legislator aimed at safeguarding the environment and the health of both the consumer and supply chain operators.

It must be considered, then, that there is now a greater awareness of the issues of environmental protection and health that increases the demand for products perceived as safer, such as organic and biodynamic.

Organic viticulture comes from a proper agronomic management, thanks to which it is possible to get the best safeguard of plants.

- The choice of the site and area development allows climatic conditions (light, ventilation, and so on) and soil (porosity, drainage, and so on) suitable for the quality of the grapes

- The hydraulic - agrarian systems represent the first and indispensable tool for land conservation;

- The genetic choices regarding "cultivar" (a cultivated plant, obtained with genetic improvement, which summarizes a set of specific morphological, physiological, and agronomic commodity of particular interest and transmissible though seed and plant parts), "clone" and "portainnesto" (the lower part of a plant multiplied by the grafting technique), should be studied to improve the ecological adaptation to the environment in relation to the Eurosystem adopted plant (which defines the amount of available environment for each plant and adjusts the amount of 'interaction between plants);

- The organic fertilization ensures the protection and slow release of nutrients;

- The cover crop helps in controlling the physiological balance of plants, improving the water-mineral nutrition, and prevents erosion and enhances the agrosystem;

- The led fight and damage thresholds indicate the moments of real need for action 
"fitoiatrico" (chemical treatment performed as a preventive measure, intended to prevent pest attacks in the bud);

- The mechanization demands and at the same time allows for greater uniformity in the vineyard;

- The proper canopy management is of strategic importance. It is significant to control the microclimate at the level of clusters and vegetation, on which depend the conditions more or less favorable for pathogens.

The most discussed aspect of organic viticulture is to prevent parasites, that are the main limitation to this kind of cultivation. The winegrowers fear of losing their product is more than justified and requires careful defence.

In the conventional chemistry fight, among fungicides (CPP) coverage, the "ditiocarbammati" (fungicides) provides excellent disease control, protected from the risk of resistance; on the other hand, are not well acceptable to many important natural limiters and the improvement of recent formulations "rameiche" (absence of cytotoxicity) allows a valid alternative also in the first stage of the season.

The most difficult choice for organic wine grower is the renunciation of the use of systemic products that, undoubtedly, has the important advantage of protecting the vegetation of formation. But, in addition to overt resistance phenomena, many bad experiences have confirmed inadequate protection of the bunch. The current phytoiatric research trends are, in fact, facing molecules with high lipophilicity and distribution capacity on the surface and in this way we have obtained excellent products for the defence of the bunch. After all, the ability to sublimate and diffuse in the gas phase is the prerogative of sulphur and cupric products. Organic viticulture therefore requires more attention and effort, but for this reason it represents a logical development of integrated agriculture and the highest professional level of the wine entrepreneur. As a result, the grapes produced according to serious and modern methods of biologic farming guarantee an excellent quality, authenticity and wholesomeness with not many risks and costs compared with conventional techniques.

The aware "wine lover", therefore, is more and more interested not only in the quality, but also in those values that include social and ethical commitment, and the safeguard of environment and territory. In the manufacturing enterprises diagrams are no longer only defined processes of viticulture and wine-making, but increasingly also the working conditions of the staff, the quantities of carbon dioxide, nitrogen oxides and sulphur emitted 
into the atmosphere, the kilowatts of electricity, cubic meters of methane, the litres of diesel consumed, the tons of destroyed waste and recycled ones, the pounds of pesticides and fertilizers used. All this aims to provide consumers with a wine which has social and environmental "benefits" measurable, verifiable and comparable.

In this way a new idea of working is being consolidated everywhere in line with a trend that many companies are interested in following in order to obtain an advantage in terms of image and profit (Menghini, 2007).

A definition of sustainable viticulture we can find it in Resolution CST 1/2008 International Organisation of Vine and Wine (OIV) ${ }^{1}$, which describes it as "Global approach commensurate with the systems of production and processing of grapes involving both the longevity of economic structures and land, obtaining quality products, taking into account the needs of a precision viticulture, risks to the environment, product safety, consumer health and enhancement of property aspects, historical, cultural, ecological and aesthetic”.

The need to share these issues on the international scale has led to the elaboration of a document "Vision on the future sustainability of our wine and vineyards"2 (Capri et al., 2014) in which they propose ideas for setting public policy and business for the sustainability of wine throughout the supply chain contemplating the environmental, social and economic, identifying innovation and cooperation keys to remove the constraints that make it difficult to implement sustainability.

Some scholars (Casini et al., 2010) have proposed a model for classifying approaches to sustainability of the cellars:

- Cellars devoted, that have a strong orientation towards sustainability and invest heavily in employee training and communication;

- Cellars unexploiters, that adopt sustainable behavior but do not communicate their actions, therefore the benefits that may result from their behavior are limited;

\footnotetext{
${ }^{1}$ The International Organisation of Vine and Wine (OIV) is an organization that operates in the interest of the international wine world that is committed to providing growers and wine producers the tools to encourage the spread of production processes consistent with the principles of sustainable development in order to avoid unfair competition and to promote dialogue in the world of production with the distribution system and society as a whole, with regard to issues of sustainability.

2 This document is the result of the international conference held in Simei in 2013 on "Sustainable viticultrure and wine production".
} 
- Cellars opportunists, that do not pay particular attention to sustainability, but tend to heavily emphasize the few sustainable practices introduced.

\section{CONCLUSION}

The set of human activities, technological progress and the uncontrolled exploitation of resources has led to heavy imbalances in the terrestrial ecosystem, risking compromising the ability of future generations to meet their own needs.

One possible solution is, therefore, represented by the sustainable development and the desire to pursue economic growth compatible with social equity. In this context, sustainability, lived in the past as more ethical than economic, is gaining importance and a much more concrete profile, designed to produce economic returns as well as on image.

The search for competitiveness aims at the objective of sustainable socio-economic, environmental and territorial pushing food companies to go out of their borders and redesign new strategies in the awareness of the new social and cultural role played.

Sustainability, although it doesn't have yet well defined contours (Warner, 2007), is a prerequisite in order to gain a sustainable competitive positioning (Borelli et al., 2010).

The actions of social responsibility should not be seen as an additional cost, but as a strategic investment in the medium and long term able to positively influence the performance of businesses and to improve the prospects of development in terms of greater visibility and better strategic positioning on market and value creation.

Indeed, companies can choose between different degrees of sustainability that are determined by a number of internal factors such as the motivation of top management, awareness of its benefits and the analysis of the cost / benefit, and external pressures groups environmentalists, regulators, standards.

The awareness that the production of quality products passes through the introduction of sustainability practices is now widespread.

It is a daunting task for the food and wine companies, especially for those of modest size, but 
we believe that the key to success for this challenge of sustainability could be identified in the ability to introduce appropriate organizational and process innovations, to network in order to create sustainability programs (especially for small farms) and in the ability to communicate effectively to the final consumer the immaterial surplus that the product contains.

\section{REFERENCES}

Agriregionieuropa (2010), Associazione Alessandro Bartola - Studi e ricerca di economia e politica agraria, Vol.6 No.20.

Annunziata, A. (2011), "L'evoluzione degli stili di consumo e la qualità alimentare", in Cesaretti, G. P., Annunziata, A., La valorizzazione sostenibile delle produzioni agroalimentari di qualità, FrancoAngeli.

Baggio, A. M., Coda, P. and Bruni, L. (2009), La crisi economica. Appello a una nuova responsabilità, Città Nuova Editrice.

Beda, A. and Bodo, R. (2006), La responsabilità sociale d'impresa. Strumenti e strategie per uno sviluppo sostenibile dell'economia, il Sole 24 Ore libri.

Borelli, I. P., Carbone, G. and Misso, R. (2010), La filiera vitivinicola campana tra mercato e società: una strategia di valorizzazione responsabile, Comunicazione presentata al XVIII Convegno Annulae della Società Italiana Agroalimentare, Venezia.

Briamonte, L. and Hinna, L. (2008), La responsabilità sociale delle imprese del sistema agroalimentare, INEA.

Campedelli, B. (2005), Reporting aziendale e sostenibilità: i nuovi orizzonti del bialncio sociale, FrancoAngeli.

Capri, E., Jordan, A., Lewis, S. E., Pretorius, I., Scienza, A., Marchis, A., Stefanucci, S., Walker, N. and Camilleri, C. (2014), Vision on the sustainable future of our wine and vineyards, UIV-SIMEI.

Casini et al, (2010).

Castellani, G. (2011), Responsabilità sociale d'impresa e bilancio di sostenibilità, Maggioli Editore.

Censis (2004), Condividere la conoscenza per progettare l'innovazione, II modello competenze per lo sviluppo locale, FrancoAngeli.

Cesaretti, P. and Sacrpato, D. (2010), Politiche integrate per uno sviluppo competitivo sostenibile dell'agroalimentare, FarncoAngeli.

Cesaretti, G. P. and Annunziata, A. (2011), La valorizzazione sostenibile delle produzioni agroalimentari di qualità, FrancoAngeli.

PAGE 194| Journal of Corporate Governance, Insurance, and Risk Management | 2015, VOL. 2, NO. 2 
Cocozza, A. (2010), Persone, Organizzazioni, Lavori: esperienze innovative di comunicazione d'impresa e valorizzazione delle risorse umane, FrancoAngeli.

Dupuis, J. C. (2005), La responsabilité sociale des entreprises comme institution: L'apport de l'approche institutionnaliste, Working Paper ESDES, Recherche no. 4.

Grunert, K. G. (2006), "Food Quality and safety: Consumer Perception and Demand", European Review of Agricoltural Economics, No.32, pp. 369-489.

Impronta etica: Il contributo dell'impresa responsabile nella creazione di valore per il territorio, 2012

Jain, T. R., Mukesh Trehan, Ranju Trehan, (2010), Business Environment (for BBA - 1), VK Enterprises, Delhi.

Menghini, S. (2007), II ruolo del settore vitivinicolo nei processi di sviluppo sostenibile, FrancoAngeli.

Modenesi, C., Tamini, G. and Verga, I.(2007), Biotecnocrazia. Informazione scientifica, agricoltura, decisione politica, Jaca Book.

Olivieri. O., Stato della legislazione sulla certificazione di qualità in Italia, documento Confagricoltura

Porter, M. E. and Kaplan, M.R. (2006), Strategy \& Society - The Link Between Competitive Advantage and Corporate Social Responsibility, Harvard Business Review.

Ricci, P. (2004), La Responsabilità Sociale d'Impresa: il ruolo e il valore della comunicazione. Atti del convegno di Benevento, 29 gennaio 2004, Pubblicazioni Dases, Franco Angeli.

Romano, D. (1998), Agricoltura e ambiente: vincoli, opportunità e strumenti per la politica agraria del 2000, Atti Convegno XXXV SIDEA.

Signorello, G., Cucuzza. G. and Pappalardo, G. (2004), "La tutela della biodiversità zootecnica italiana nei piani regionali di sviluppo rurale", Rivista di economia agraria, No.1.

SMEA, (2014), Istituto di servizi per il mercato agricolo alimentare, Avanti adagio l'export agroalimentare

Trisorio, A. (2004), Misurare la sostenibilità, Indicatori per l'agricoltura italiana, INEA.

Unioncamere, Rapporto Nazionale sul settore vitivinicolo 2009 in Italia.

Warner, K. D. (2007), "The quality of sustainability: Agroecological partnerships and the geographic branding of California winegrapes", Journal of Rural Studies, 23, pp. 142-155.

Werther, W. B. and Chandler, D. (2010), Strategic Corporate Social Responsability: Stakeholders in a Global Environment, Sage Publications.

PAGE 195| Journal of Corporate Governance, Insurance, and Risk Management | 2015, VOL. 2, NO. 2 
http://www.assoenologi.it/main/index.php?pages=comunicati-studi

http://www.legambiente.it/dettaglio

http://www.improntaetica.org 